\title{
Valorização do resíduo da casca de jabuticaba (Myrciaria cauliflora) para produção da exo-poligalacturonase com Aspergillus niger CCT 0916
}

Valorization of the residue of the jabuticaba bark (Myrciaria cauliflora) for the production of exopolygalacturonase with Aspergillus niger CCT 0916

Valorización del residuo de corteza de jabuticaba (Myrciaria cauliflora) para la producción de exopoligalacturonasa con Aspergillus niger CCT 0916

\section{Resumo}

O presente trabalho teve como objetivo estudar o potencial do resíduo seco da casca de jabuticaba (Myrciaria cauliflora) como substrato na produção da exo-poligalacturonase (Exo-PG) por meio da fermentação em estado sólido (FES) utilizando o micro-organismo Aspergillus niger CCT 0916 como agente da fermentação. As cascas de jabuticaba foram secas em estufa com circulação de ar a $55^{\circ} \mathrm{C}$ com velocidade de ar de $1.0 \mathrm{~m} / \mathrm{s}$ e logo em seguida trituradas para obtenção do resíduo seco, o qual foi caracterizado. Foi realizado uma fermentação em estado sólido no período de 0 a 72 horas, durante esse período foram analisados os seguintes parâmetros: umidade do meio, $\mathrm{pH}$, açúcares redutores e atividade poligalacturonásica (APG). Foram encontrados altos teores de açúcares redutores e pectina no resíduo seco da casca da jabuticaba (RSJ). As isotermas de adsorção mostraram que a atividade de água adequada para o processo fermentativo deve ser acima de 0.7. O pico máximo da APG foi de 16,12 U/g do meio fermentado alcançado em $72 \mathrm{~h}$ de cultivo, portanto este resíduo é potencialmente viável como substrato na síntese da Exo-PG por fermentação em estado sólido. Palavras-chave: Aspergillus niger; Enzima; Fermentação em estado sólido; Resíduo agroindustrial.

\section{Abstract}

This work aimed to study the potential of dry residue from jabuticaba bark (Myrciaria cauliflora) as a substrate in the production of exo-polygalacturonase (Exo-PG) through solid state fermentation (FES) using the microorganism Aspergillus niger CCT 0916 as a fermentation agent. The jabuticaba peels were dried in an oven with air circulation at $55^{\circ} \mathrm{C}$ with an air speed of $1.0 \mathrm{~m} / \mathrm{s}$ and then crushed to obtain the dry residue, which was characterized. A solid state fermentation was carried out in the period from 0 to 72 hours, during this period the following parameters were analyzed: moisture of the medium, $\mathrm{pH}$, reducing sugars and polygalacturonic activity (APG). High levels of reducing sugars and pectin were found in the dry residue of the jabuticaba bark (RSJ). The adsorption isotherms showed that the adequate water activity for the fermentation process must be above 0.7 . The maximum peak of APG was $16.12 \mathrm{U} / \mathrm{g}$ of the 
fermented medium reached in $72 \mathrm{~h}$ of culture, therefore this residue is potentially viable as a substrate in the synthesis of Exo-PG by solid state fermentation.

Keywords: Aspergillus niger; Enzyme; Solid state fermentation; Agro-industrial residue.

\section{Resumen}

Este trabajo tuvo como objetivo estudiar el potencial del residuo seco de la corteza de jabuticaba (Myrciaria cauliflora) como sustrato en la producción de exopoligalacturonasa (Exo-PG) mediante fermentación en estado sólido (FES) utilizando el microorganismo Aspergillus niger CCT 0916 como agente de fermentación. Las cáscaras de jabuticaba se secaron en un horno con circulación de aire a $55^{\circ} \mathrm{C}$ con una velocidad de aire de $1.0 \mathrm{~m} / \mathrm{s}$ y luego se trituraron para obtener el residuo seco, el cual se caracterizó. Se realizó una fermentación en estado sólido en el período de 0 a 72 horas, durante este período se analizaron los siguientes parámetros: humedad del medio, $\mathrm{pH}$, azúcares reductores y actividad poligalacturónica (APG). Se encontraron altos niveles de azúcares reductores y pectina en el residuo seco de la corteza de jabuticaba (RSJ). Las isotermas de adsorción mostraron que la actividad de agua adecuada para el proceso de fermentación debe ser superior a 0,7. El pico máximo de APG fue de 16,12 U/g del medio fermentado alcanzado en $72 \mathrm{~h}$ de cultivo, por lo que este residuo es potencialmente viable como sustrato en la síntesis de Exo-PG por fermentación en estado sólido.

Palabras clave: Aspergillus niger; Enzima; Fermentación en estado sólido; Residuo agroindustrial.

\section{Introdução}

Normalmente as cascas das frutas são descartadas, correspondendo cerca de 30 a $43 \%$ do fruto, gerando grandes quantidades de resíduos e provocando impacto ambiental devido ao lançamento excessivo no meio ambiente (Alezandro et al., 2013). A indústria de processamento de frutas está em constante expansão, porém o aumento da sua capacidade produtiva tem como consequência a geração de um maior volume de resíduos sólidos, estima-se que quase 1.3 bilhão de toneladas/ano de subprodutos seja produzido em todo o mundo, que são caracterizados por possuírem elevado valor orgânico e por representarem um problema ambiental quando descartados de maneira inadequada (Martins et al., 2019; Gupta et al., 2019).

A jabuticaba é considerada uma superfruta devido às suas propriedades nutricionais. Além disso, a casca de jabuticaba é rica em carboidratos, fibras, sais minerais, aminoácidos, ácido ascórbico, compostos fenólicos e vitaminas B1 e B2 (Chang et al., 2018). A consolidação do conceito de biorrefinaria promoveu mudanças na gestão dos resíduos de frutas para a produção de biocombustíveis, materiais, produtos químicos e enzimas (Joglekar et al., 2019). A fermentação em estado sólido (FES) é geralmente conduzida em escala comercial pela indústria de alimentos para o tratamento e reutilização de resíduos agroindustriais. Nestes processos, as enzimas produzidas pelos microrganismos para digerir os resíduos têm uma profunda influência na estrutura, atividade biológica e biodisponibilidade do subproduto (Mao et al., 2020).

Além disso, o FES usando Aspergillus niger é um processo viável porque aproveita os resíduos da agroindústria como substrato no processo fermentativo, minimiza os custos de tratamento destes e os problemas ambientais (Utami et al., 2017). As poligalacturonases (PG) são enzimas pectinolíticas que clivam as ligações $\alpha$-1,4-glicosídicas que ligam o ácido galacturônico. Dentre essas enzimas, a exo-poligalacturonases (EC 3.2.1.67) atua no lado não redutor e hidrólise os ácidos pécticos e libera mono-galacturonato (Patidar et al., 2018).

Portanto, o presente trabalho teve como objetivo estudar o potencial do resíduo seco da casca de jabuticaba (Myrciaria cauliflora) como substrato na produção da Exo-PG, por meio da fermentação em estado sólido (FES), utilizando o microorganismo Aspergillus niger CCT 0916 como agente da fermentação.

\section{Metodologia}

Uma pesquisa é feita para trazer novos saberes para a sociedade como preconiza Pereira et al. (2018). A presente pesquisa foi laboratorial com característica quantitativa. A jabuticaba (Myrciaria cauliflora) de variedade Sabará foi adquirida na EMPASA (Empresa Paraibana de Abastecimento e Serviços Agrícolas) na cidade de Campina Grande-PB em estádio maduro de maturação. A fruta foi lavada e sanitizada com solução aquosa de hipoclorito de sódio na concentração de $200 \mathrm{mg} / \mathrm{L}$ de cloro 
livre por 15 min e em seguida enxaguada com água corrente, seguido do processo de seleção e classificação. Na Figura 1 são apresentados os frutos inteiros e as cascas frescas da jabuticaba.

Figura 1. Frutos inteiros (A) e cascas frescas (B) da jabuticaba variedade Sabará.
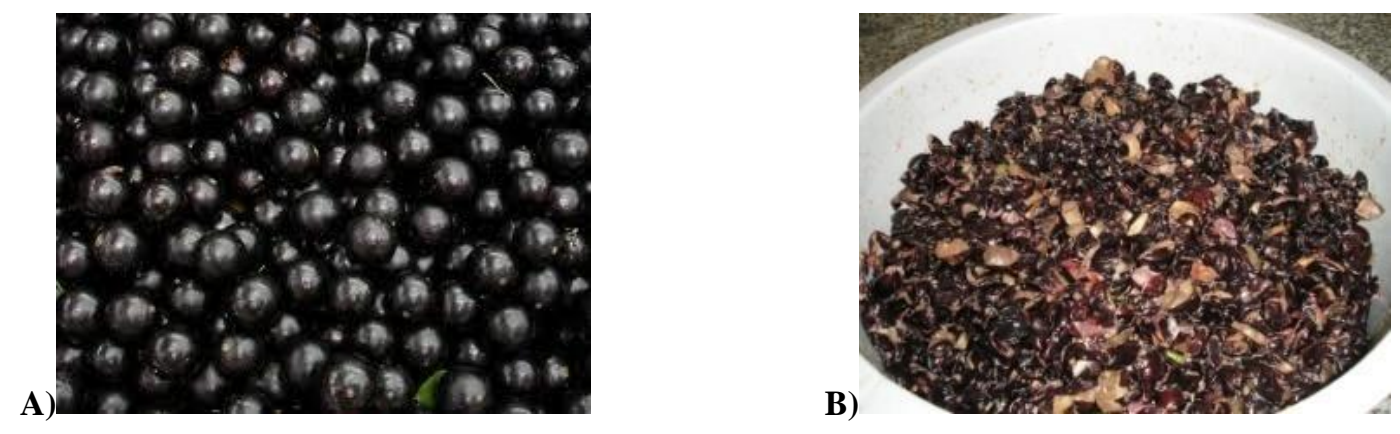

Fonte: Autores (2020).

Após a seleção e classificação, os frutos foram esmagados com o objetivo de separar a casca (Figura 1B) da polpa. Ambos os processos foram realizados de forma manual.

\subsection{Preparação do resíduo da casca de jabuticaba}

As cascas foram pesadas individualmente, trituradas em liquidificador industrial (Fabricante Kohlbach, modelo KM42A), pesadas e colocadas em bandejas de alumínio em estufa com circulação forçada de ar (Fabricante Marconi, modelo MA048) com velocidade de ar de $1.0 \mathrm{~m} / \mathrm{s}$ a temperatura de $55^{\circ} \mathrm{C}$ até massa constante. Após a secagem, foram moídas em moinho de facas (Fabricante Marconi, modelo MA 048), e denominada de resíduos secos de jabuticaba de (RSJ). Foram armazenados em embalagens laminadas compostas por duas camadas de PET-met (poliéster - tereftalato de polietileno metalizado) com uma espessura de $12 \mu \mathrm{m}$.

\subsection{Caracterização físico-química do resíduo seco}

As análises físico-químicas realizadas foram: $\mathrm{pH}$, umidade, cinzas, sólidos solúveis totais ( ${ }^{\circ}$ Brix) e proteína (A.O.A.C, 2016). Para determinação do teor de açúcares totais e redutores foi utilizada a metodologia proposta por Miller (1959). O método proposto por Rangana (2004) foi usado para quantificar o conteúdo de pectina.

\subsection{Isotermas de adsorção de umidade do resíduo}

Para a construção das isotermas foram pesados $20 \mathrm{~g}$ do resíduo seco das casca de jabuticaba e adicionado aos mesmos, água destilada na proporção de 1:1. Em seguida foi submetido à homogeneização por 30 minutos e deixado em repouso no refrigerador em recipiente hermético por 24 h. Foi coletado $1 \mathrm{~g}$ de cada, e transferido para cápsulas de alumínio, o qual foi levado para o equipamento Thermoconstanter Novasina RTD 200 TH2 para a realização das leituras de atividade de água nas temperaturas de 25,30 e $35^{\circ} \mathrm{C}$. As isotermas de adsorção de umidade foram construídas com os dados de umidade de equilíbrio e atividade de água, onde as curvas foram ajustadas usando o modelo matemático de Guggenheim-Anderson de Boer (GAB).

\subsection{Processo fermentativo}

Para o processo fermentativo do resíduo seco foi utilizado uma concentração de 1,5\% de fonte de nitrogênio (sulfato de amônio) e umidade inicial do meio de $40 \%$, condições determinadas por meio de testes preliminares, variando a umidade de 40 a $60 \%$ e a fonte de nitrogênio de 0,5 a $1,5 \%$, onde foi avaliada a atividade poligacturonásica (APG). 
O micro-organismo utilizado nesta pesquisa foi o fungo filamentoso Aspergillus niger CCT 0916, cedido pela Embrapa Agroindústria Tropical, com sede em Fortaleza-CE, e conservado no Laboratório de Engenharia Bioquímica (LEB/UAEQ/UFCG), em tubos de ensaio com tampas rosqueadas contendo solo estéril, mantidos a $-18^{\circ} \mathrm{C}$.

Os conídios foram removidos do solo estéril com uma alça de platina e transferidos para tubos de ensaio contendo meio básico. O meio foi previamente esterilizado em autoclave por $20 \mathrm{~min}$ a $0,5 \mathrm{~atm}$ e consiste em pectina cítrica (10 g/L), $\mathrm{NaNO}_{3}(3$ $\mathrm{g} / \mathrm{L}), \mathrm{KH}_{2} \mathrm{PO}_{4}(1 \mathrm{~g} / \mathrm{L}), \mathrm{MgSO}_{4}(0,5 \mathrm{~g} / \mathrm{L}), \mathrm{KCl}(0,5 \mathrm{~g} / \mathrm{L}), \mathrm{FeSO}_{4} 7 \mathrm{H} 2 \mathrm{O}(0,01 \mathrm{~g} / \mathrm{L})$ e ágar-ágar $(20 \mathrm{~g} / \mathrm{L})$. Os tubos de ensaio foram inclinados, trazidos à temperatura ambiente e incubados por cinco dias em incubadora a $30^{\circ} \mathrm{C}$ (Couri et al., 2000). Após esse período, os tubos de ensaio foram mantidos em geladeira por quatro meses. Foram preparadas três soluções: solução A (fosfato de potássio monobásico $200 \mathrm{~g} / \mathrm{L})$, solução B (3,96 g de sulfato de zinco, 4,6 g de sulfato de ferro. 0,01 g de sulfato de manganês e 0,5 mL de ácido sulfúrico PA) e uma solução umedecedora ( $0,19 \mathrm{~mL}$ de solução $\mathrm{A}, 0,025 \mathrm{~mL}$ de solução B e $2,8 \mathrm{~g}$ de peptona). A cada frasco foram adicionados 4,60 g de sabugo de milho desidratado $6 \mathrm{~mL}$ de meio umedecedor e, a seguir, os frascos foram fechados, homogeneizados e esterilizados em autoclave a $120^{\circ} \mathrm{C}$ por $30 \mathrm{~min}$. Utilizando uma alça de platina, os microrganismos foram retirados dos tubos de ensaio e colocados nos frascos contendo a sabugo de milho esterilizado. Em seguida, os frascos foram incubados em incubadora bacteriológica (SL 101, Solab, São Paulo) a $30{ }^{\circ} \mathrm{C}$ por um período de cinco dias. Após a incubação, os frascos foram armazenados sob refrigeração e utilizados como inóculo para os testes de fermentação (Souza et al. 2010).

\subsubsection{Preparação do meio de cultivo para a fermentação e inoculação}

Foi pesado em um béquer $80 \mathrm{~g}$ do resíduo seco e adicionado água na porcentagem de $40 \%$ e sulfato de amônio na concentração de $1.5 \%$. Após a homogeneização foram distribuídos $10 \mathrm{~g}$ desse meio úmido nos erlenmeyers, os quais foram tampados e levados para a autoclave a 1 atm por $15 \mathrm{~min}$, logo em seguida foram resfriados.

Foram inoculados $10^{7}$ esporos de Aspergillus niger CCT 0916/g de meio, os quais foram incubados em estufa bacteriológica (Fabricante Solab, Modelo SL-101) a temperatura de $30 \pm 2{ }^{\circ} \mathrm{C}$, seguindo o estudo de Souza et al. (2010). O processo fermentativo teve duração de 72 h, no qual foram retiradas amostras periodicamente nos tempos de $(0,7,22,30,44$, 50, 66, 72 h de fermentação) para a realização das análises de umidade (U), açúcares redutores (AR), pH e atividade poligalacturonásica (APG). A extração do complexo enzimático foi realizada seguindo a metodologia de Castilho et al. (2000), enquanto que a atividade exo-poligalacturonase foi determinada conforme Couri et al. (2000).

\section{Resultados e Discussão}

\subsection{Caracterização físico-química do resíduo seco}

A jabuticaba apresentou $31.10 \%$ de rendimento para as cascas frescas e $4.28 \%$ para o resíduo seco (RSJ). Os dados da Tabela 1 correspondem aos resultados da caracterização físico-química do resíduo seco de jabuticaba (RSJ). 
Tabela 1. Caracterização físico-química do resíduo seco da casca de jabuticaba.

\begin{tabular}{cc}
\hline Parâmetros & RSJ \\
\hline Umidade (\% b.u)* & $9,70 \pm 0,17$ \\
Cinzas (\%) & $2,70 \pm 0,06$ \\
Proteína (\%) & $4,39 \pm 0,35$ \\
Pectina (\%) & $8,31 \pm 0,24$ \\
Açúcar total (\%) & $27,45 \pm 1,10$ \\
Açúcar redutor $(\%)$ & $24,67 \pm 0,31$ \\
Sólidos solúveis $\left({ }^{\circ}\right.$ Brix $)$ & $38,00 \pm 0,10$ \\
pH & $3,60 \pm 0,10$ \\
\hline
\end{tabular}

*Nota: b.u é base úmida. Fonte: Autores (2020).

Os valores obtidos da umidade estão dentro dos limites estabelecidos pela Agência Nacional de Vigilância Sanitária (ANVISA), que estabelece o máximo de $15 \%$ (b.u) de umidade para farinhas. Na fermentação em estado sólido a quantidade de água presente nos substratos é um parâmetro limitante, pois pode afetar diretamente o crescimento dos micro-organismos, assim como a síntese de metabólitos.

O teor de cinzas do resíduo seco jabuticaba de 2,70\% estão próximos do valor encontrado por Alves et al. (2014) de $3,41 \%$ para a casca de jabuticaba. O resíduo da jabuticaba apresentou teor proteico 4,39\%, valor inferior aos obtidos por Ferreira et al. (2012) de 5,23\%, Appelt et al. (2015) e Alves et al. (2013), 6,40\% e 6,06\%.

O resíduo seco estudado apresentou o valor de $8,31 \%$ de pectina, considerado alto, que segundo a literatura esta substância química atua como eficiente fonte indutora na produção de enzimas pectinolíticas, assim como também pode atuar como fonte de carbono para os micro-organismos dependendo da quantidade de açúcares presentes no meio de cultivo. Fontana et al. (2005) estudaram o efeito da quantidade de pectina em um meio a base de farelo de trigo e observaram que até $16 \%$ de pectina não ocorreu repressão na síntese das pectinases produzidas pelo Aspergillus niger.

Os valores que foram encontrados de açúcares totais e redutores foram $27.45 \%$ e $24,67 \%$, respectivamente. Lima et al. (2011) para casca de jabuticabada da espécie Sabará obtiveram os valores de 38,93 e 33,24 g $100 \mathrm{~g}^{-1}$ para açúcares totais e redutores, respectivamente. O valor de pH para o RSJ foi de 3.60, este parâmetro tem grande influência na fermentação em estado sólido ou cultivo semissólido, visto que o crescimento dos micro-organismos depende do valor inicial do pH do meio, o qual para o Aspergillus niger o mínimo é de 1,2 e o ótimo está entre 3,0 e 6,0 (Franco, 1999). Malvessi \& Silveira (2004) utilizaram um meio contendo farelo de trigo, sais minerais e pectina na produção da enzima poligalacturonase variando o pH entre 2 a 7 e obtiveram máxima atividade com pH inicial do meio de 4.0. Gurak et al., (2014) encontraram valor de pH de 3.45 para a casca de jabuticaba.

\subsection{Modelagem das isotermas de adsorção de umidade}

Os dados da Tabela 2 correspondem aos resultados dos parâmetros de ajuste do modelo de GAB para as isotermas de adsorção para o resíduo da casca de jabuticaba. 
Research, Society and Development, v. 10, n. 1, e13810111592, 2021

(CC BY 4.0) | ISSN 2525-3409 | DOI: http://dx.doi.org/10.33448/rsd-v10i1.11592

Tabela 2. Parâmetros de ajuste do modelo GAB para o resíduo da casca de jabuticaba.

\begin{tabular}{ccccc}
\hline Temperatura $\left({ }^{\circ} \mathbf{C}\right)$ & $\mathbf{X m}$ & $\mathbf{C}$ & $\mathbf{K}$ & $\mathbf{R}^{\mathbf{2}}$ \\
\hline 25 & 0,0978 & 25,923 & 1,008 & 0,9966 \\
30 & 0,0892 & 8,387 & 0,9857 & 0,9991 \\
35 & 0,1379 & 8,205 & 0,9592 & 0,9948 \\
\hline
\end{tabular}

Fonte: Autores (2020).

Observando os parâmetros do modelo de GAB (Tabela 2) pode-se verificar que os valores de Xm que representa a fração de umidade na monocamada do material adsorvente, sofre reduções com o aumento da temperatura no intervalo entre 25 e $30{ }^{\circ} \mathrm{C}$. Entre 30 e $35^{\circ} \mathrm{C}$ houve uma elevação tanto para o RSJ, fato igualmente verificado por Alcântara et al. (2009) quando utilizaram pedúnculo seco de caju.

Os valores do parâmetro C segundo Muniz et al. (2020) representa a diferença na energia de sorção molar para a água na monocamada em comparação com as camadas superiores. No presente estudo não apresentam tendência bem definida sob o aumento de temperatura. Segundo Vieira et al. (2007) os valores de C estão muito abaixo de 200, estando portanto dentro da faixa comumente encontrada na literatura. Quanto ao parâmetro K, o qual representa o fator de correção das propriedades das moléculas na multicamada com relação ao volume do líquido (Silva et al., 2020), observa-se valores próximos a um (1), variando entre 0,9948 e 0,9991 . Os valores dos coeficientes de determinação $\left(\mathrm{R}^{2}\right)$ estão acima de 0,99 o que indica que o modelo pode ser utilizado na predição das isotermas de adsorção do resíduo seco estudado.

Foram construídas as isotermas de adsorção de umidade do resíduo seco da jabuticaba (RSJ) nas temperaturas de 25 , 30 e $35^{\circ} \mathrm{C}$, onde a equação matemática de GAB foi aplicada aos dados. Por meio destas foi possível verificar a umidade contida no resíduo seco, assim como determinar o intervalo de atividade de água favorável ao desenvolvimento do fungo Aspergillus niger CCT 0916. Os respectivos valores de umidade de equilíbrio (Ueq) em função da atividade de água (Aw) estão representadas na Figura 2.

Figura 2. Ajuste do modelo GAB a isoterma de adsorção de água.

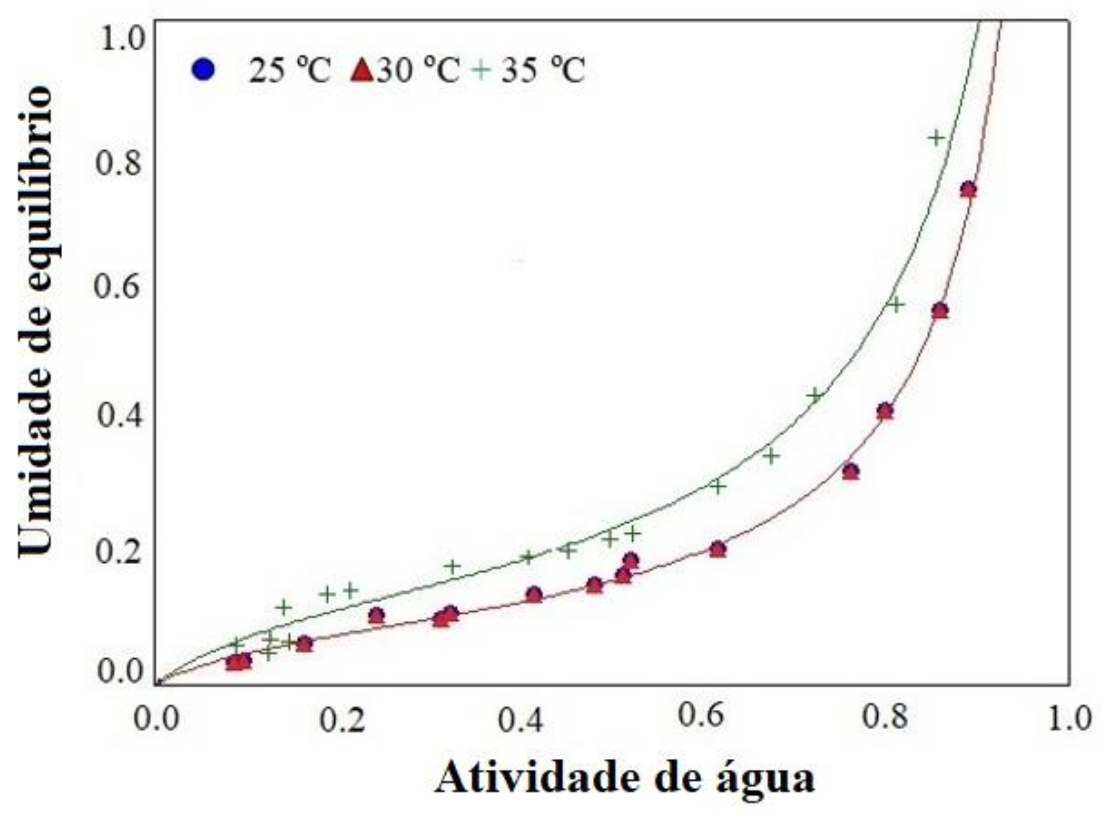

Fonte: Autores (2020). 
Observa-se que a umidade de equilíbrio (Ueq) aumenta com o aumento da atividade de água ( $\mathrm{A}_{\mathrm{w}}$ ) (Figura 2). As isotermas para as três temperaturas estudadas são classificadas como do tipo III de acordo com a classificação de Brunauer et al. (1938) e apresentam a forma de J.

Para o RSJ houve um distanciamento das curvas à medida que a $A_{w}$ aumenta, para o intervalo entre 25 e $30{ }^{\circ} \mathrm{C}$ o efeito desta variável só é percebido entre 0.1 e 0.7 de atividade de água, intervalo no qual segundo dados de literatura não há desenvolvimento do micro-organismo Aspergillus niger, portanto, é necessário que na utilização destes substratos em uma fermentação em estado sólido, a atividade de água esteja acima de 0.7 .

\subsection{Acompanhamento cinético do processo fermentativo para o resíduo seco da jabuticaba}

A Figura 3 corresponde ao acompanhamento cinético da maior produção da Exo-PG e do consumo de açúcares redutores, assim como o monitoramento do $\mathrm{pH}$ e da umidade (b.u), durante o período de 72 horas de fermentação em estado sólido nas condições de: concentração de nitrogênio de (1.5\%) e umidade de $40 \%$, correspondendo a atividade de água (Aw) de 0.88 .

Figura 3. Cinética de fermentação para a produção do exo-poligalacturonase.

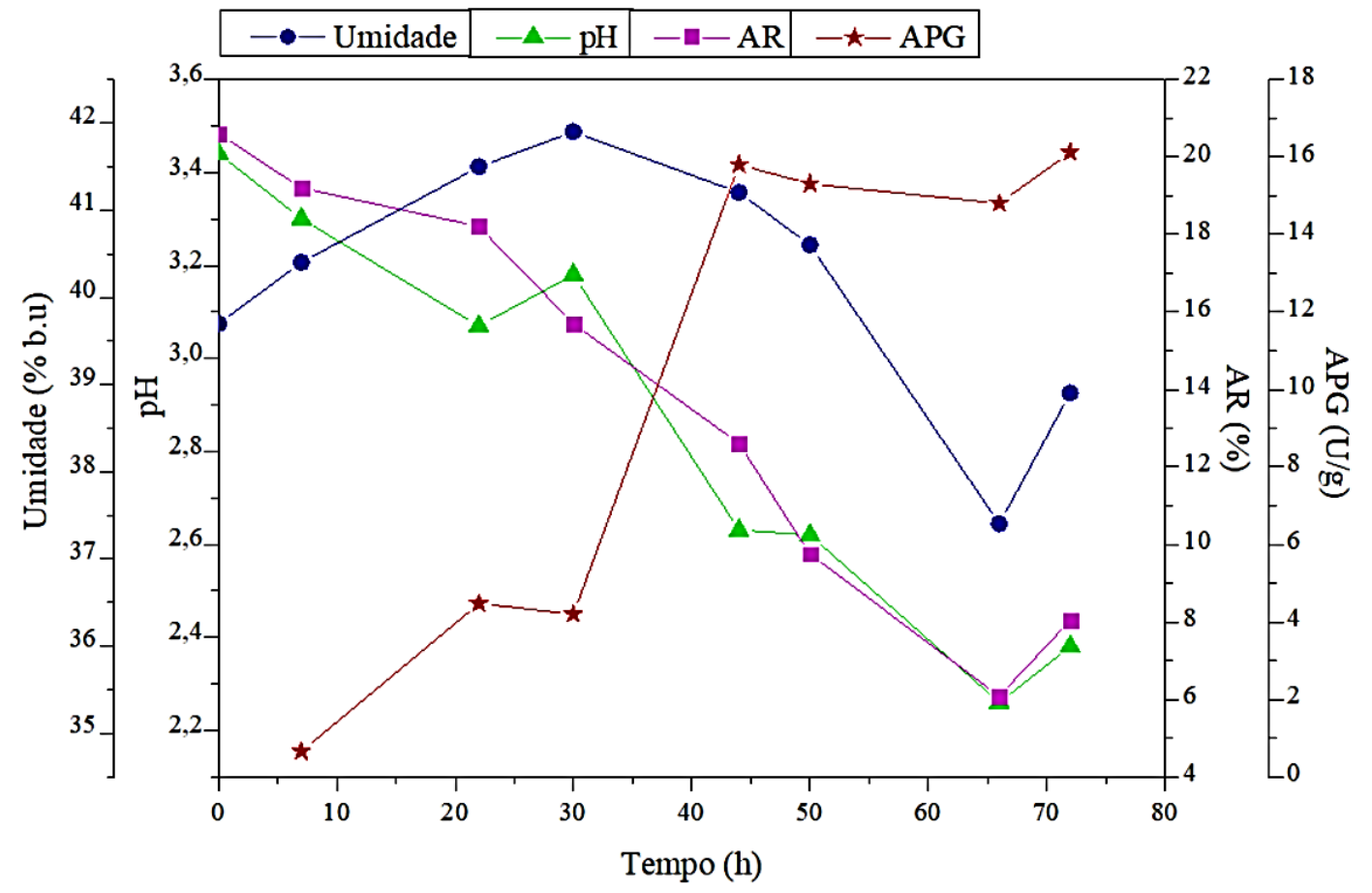

Fonte: Autores (2020).

A umidade do meio variou entre 41,9 a 37,4\%. Estas perdas de água segundo Borzani et al. (2011) são devidas à evaporação de água e as atividades metabólicas microbianas ocorridas durante o processo fermentativo.

$\mathrm{O}$ pH inicial do meio foi de 3,44 e durante o cultivo reduziu para 2,38, provavelmente devido a secreção de ácidos orgânicos pelo micro-organismo. A concentração de açúcares redutores (AR) no início do cultivo foi de 20,6\%, diminuindo lentamente até a $66^{\text {a }}$ hora de cultivo chegando a $6,08 \%$, após esse período observa-se um acúmulo destes no meio, possivelmente devido a hidrólise da pectina em oligossacarídeos e monossacarídeos. Segundo Fenema (2010) a pectina em meio ácido as ligações glicosídicas $(1,4)$ são hidrolisadas originando moléculas de D-galactose, L-arabinose, D-xilose, L-ramnose e L-fucose. 
A partir das 7 horas de processo, verifica-se o início da produção da exo-poligalacturonase e entre a $30^{\mathrm{a}}$ hora até a $66^{\mathrm{a}}$ hora de cultivo percebe-se uma grande variação na curva de AR simultaneamente com a atividade enzimática atingindo, 15,8 U/g em 44 horas de fermentação. No intervalo de tempo entre $44^{\mathrm{a}}$ e $66^{\mathrm{a}}$ horas não houve variação na APG, embora tenha ocorrido grande consumo dos açúcares. Logo, neste caso o consumo preferencial de açúcares pelo micro-organismo não favoreceu a produção da poligacturonase (PG). Entre $66^{\mathrm{a}}$ e $72^{\mathrm{a}}$ horas a atividade voltou a subir $(16,12 \mathrm{U} / \mathrm{g})$, possivelmente o micro-organismo utilizou os açúcares da hidrólise da pectina como fonte de carbono e produziu a enzima.

Souza et al. (2010) ao estudarem a produção de PG por fermentação semissólida utilizando resíduo do maracujá como substrato, reportaram que a atividade PG começou a partir de $7 \mathrm{~h}$ de fermentação sendo atingido um pico de atividade igual a 20,9 U/g em $66 \mathrm{~h}$ de processo.

\section{Conclusão}

Os resultados da caracterização físico-química do resíduo seco da casca da jabuticaba exibem valores satisfatórios de $\mathrm{pH}$, açúcares redutores e pectina, apontando que este pode ser utilizado como substrato em processos fermentativos. O modelo de $\mathrm{GAB}$ ajustou-se adequadamente às isotermas de adsorção nas temperaturas de 25,30 e $35^{\circ} \mathrm{C}$, havendo correlação entre os coeficientes de determinação, com valores de 0,99. O maior valor da atividade da exo-poligalacturonase (16,12 U/g) foi alcançado em 72 horas de fermentação. Portanto o resíduo seco da casca de jabuticaba (RSJ) é potencialmente viável como substrato na síntese da Exo-PG por fermentação em estado sólido.

Como sugestão de trabalhos futuros pode ser feito a otimização no processo de extração, utilizar técnicas para purificar e recuperar a enzima obtida. Pode-se utilizar a enzima obtida na etapa de clarificação de sucos.

\section{Referências}

AOAC. 2016. Official methods of analysis of AOAC International (20a ed). AOAC international.

Alcântara, S. R., Almeida, F. D. A., Silva, F. L. D., \& Gomes, J. P. (2009). Isotermas de adsorção do pedúnculo seco do caju. Rev. bras. eng. agríc. ambient, 81-87.

Alezandro, M. R., Granato, D., \& Genovese, M. I. (2013). Jaboticaba (Myrciaria jaboticaba (Vell.) Berg), a Brazilian grape-like fruit, improves plasma lipid profile in streptozotocin-mediated oxidative stress in diabetic rats. Food Research International, 54(1), 650-659.

Alves, A. P. C., Corrêa, A. D., Alves, D. S., Saczk, A. A., Lino, J. B., \& Carvalho, G. A. (2014). Toxicity of the phenolic extract from jabuticabeira (Myrciaria cauliflora (Mart.) O. Berg) fruit skins on Spodoptera frugiperda. Chilean journal of agricultural research, 74(2), $200-204$.

Alves, A. P. C, Corrêa, A. D., Pinheiro, A. C. M., \& de Oliveira, F. C. (2013). Flour and anthocyanin extracts of jaboticaba skins used as a natural dye in yogurt. International journal of food science \& technology, 48(10), 2007-2013.

Appelt, P., da Cunha, M. A. A., Guerra, A. P., Kalinke, C., \& de Lima, V. A. (2015). Development and characterization of cereal bars made with flour of jabuticaba peel and okara. Acta Scientiarum. Technology, 37(1), 117-122.

Borzani, W., Schmidell, W., Lima, U.A., Aquarone, E. (2011) Biotecnologia Industrial: fundamentos. Edgard Blucher, 254.

Brauneur, S., Emmet, P., \& Teller, E. (1938). Adsorption of gases in multi molecular layer. Journal of Am. Chemical. Soc, 60, 309.

Castilho, L. R., Medronho, R. A., \& Alves, T. L. (2000). Production and extraction of pectinases obtained by solid state fermentation of agroindustrial residues with Aspergillus niger. Bioresource Technology, 71(1), 45-50.

Chang, S., Tang, H., Wu, H., Su, X., Lewis, A., \& Ji, C. (2018). Three-Dimensional Modelling and Simulation of the Ice Accretion Process on Aircraft Wings. International Journal of Astronautics and Aeronautical Engineering .

Couri, S., da Costa Terzi, S., Pinto, G. A. S., Freitas, S. P., \& da Costa, A. C. A. (2000). Hydrolytic enzyme production in solid-state fermentation by Aspergillus niger 3T5B8. Process Biochemistry, 36(3), 255-261.

Fennema, O. R., Damodaran, S., Parkin, K. (2010) Química de Alimentos, (4a ed.), Artmed, 900p.

Ferreira, A. E., Ferreira, B. S., Burgarelli LAGES, M. M., Felício Rodrigues, V. A., \& Dessimoni Pinto, N. A. V. (2012). Produção, caracterização e utilização da farinha de casca de jabuticaba em biscoitos tipo cookie. Brazilian Journal of Food \& Nutrition/Alimentos e Nutrição, 23(4).

Fontana, R. C., Salvador, S., \& Da Silveira, M. M. (2005). Influence of pectin and glucose on growth and polygalacturonase production by Aspergillus niger in solid-state cultivation. Journal of Industrial Microbiology and Biotechnology, 32(8), 371-377. 
Franco, B. D. G. M. (1999). Microbiologia dos alimentos. Editora-Atheneu, 182p.

Gupta, N., Poddar, K., Sarkar, D., Kumari, N., Padhan, B., \& Sarkar, A. (2019). Fruit waste management by pigment production and utilization of residual as bioadsorbent. Journal of environmental management, 244, 138-143.

Gurak, P. D., De Bona, G. S., Tessaro, I. C., \& Marczak, L. D. F. (2014). Jaboticaba pomace powder obtained as a co-product of juice extraction: a comparative study of powder obtained from peel and whole fruit. Food Research International, 62, 786-792.

Joglekar, S. N., Pathak, P. D., Mandavgane, S. A., \& Kulkarni, B. D. (2019). Process of fruit peel waste biorefinery: a case study of citrus waste biorefinery, its environmental impacts and recommendations. Environmental Science and Pollution Research, 26(34), 34713-34722.

Lima, A. D. J. B., Correa, A. D., Saczk, A. A., Martins, M. P., \& Castilho, R. O. (2011). Anthocyanins, pigment stability and antioxidant activity in jabuticaba [Myrciaria cauliflora (Mart.) O. Berg]. Revista Brasileira de Fruticultura, 33(3), 877-887.

Malvessi, E., \& Silveira, M. M. D. (2004). Influence of medium composition and pH on the production of polygalacturonases by Aspergillus oryzae. Brazilian Archives of Biology and technology, 47(5), 693-702.

Mao, M., Wang, P., Shi, K., Lu, Z., Bie, X., Zhao, H., \& Lv, F. (2020). Effect of solid state fermentation by Enterococcus faecalis M2 on antioxidant and nutritional properties of wheat bran. Journal of Cereal Science, 102997.

Martins, Q. S. A., de Barros, H. E. A., da Cunha, S. L., Gualberto, S. A., \& da Silva, M. V. (2019). Resíduos da indústria processadora de polpas e frutas: capacidade antioxidante e fatores antinutricionais. Revista em Agronegócio e Meio Ambiente, 12(2), 591-608.

Miller, G. L. (1959). Use of dinitrosalicylic acid reagent for determination of reducing sugar. Analytical chemistry, 31(3), 426-428.

Muniz, C. E. S., Santiago, Â. M., Gusmão, T. A. S., Oliveira, H. M. L., de Sousa Conrado, L., \& de Gusmão, R. P. (2020). Solid-state fermentation for singlecell protein enrichment of guava and cashew by-products and inclusion on cereal bars. Biocatalysis and Agricultural Biotechnology, 101576.

Patidar, M. K., Nighojkar, S., Kumar, A., \& Nighojkar, A. (2018). Pectinolytic enzymes-solid state fermentation, assay methods and applications in fruit juice industries: a review. 3 Biotech, 8(4), 199.

Pereira, AS, Shtsuka, DM, Parreira, FJ \& Shitsuka, R. (2018). Metodologia da pesquisa científica. [e-book]. Santa Maria. Ed. UAB/NTE/UFSM. Acesso em: 31 dezembro 2020. https://repositorio.ufsm.br/bitstream/handle/1/15824/Lic_Computacao_Metodologia-Pesquisa-Cientifica.pdf?sequence=1.

Ranagara, S. 2004. Manual of analysis of fruit and vegetable products New Delhi.

Silva, H. A., Gomes, J. P., \& de Melo Queiroz, A. J. (2020). Hygroscopic Behavior and Thermodynamic Properties of Ziziphus joazeiro Mart. Kernel Flour. Journal of Agricultural Studies, 8(3), 50-62.

Souza, R. L., Oliveira, L. D. S., da Silva, F. L., \& Amorim, B. C. (2010). Caracterização da poligalacturonase produzida por fermentação semi-sólida utilizandose resíduo do maracujá como substrato. Revista Brasileira de Engenharia Agrícola e Ambiental, 14(9), 987-992.

Utami, T. S., Hariyani, I., Alamsyah, G., \& Hermansyah, H. (2017). Production of dry extract extracellular lipase from Aspergillus niger by solid state fermentation method to catalyze biodiesel synthesis. Energy Procedia, 136, 41-46.

Vieira, A. H., de Figueirêdo, R. M. F., \& de Melo Queiroz, A. J. (2007). Isotermas de adsorção de umidade da pitanga em pó. Revista de Biologia e Ciências da Terra, 7(1), 11-20. 